RESUMEN: Según Bataille, los fundamentos de la comunidad humana, y el sentido de sus actividades, no radican en principios externos sino, muy al contrario, en la interioridad de los hombres, lo que implica la imposibilidad objetiva de su estudio y, necesariamente, una intimidad de la subjetividad.

Palabras Clave: Comunidad, Bataille, sacrificio, sentido, soberanía, subjetividad.
ABSTRACT: According to Bataillle, the foundations of the human community and the meaning of its activities do not rest on external principles but in contrast on man's internal life which precludes any objective study and implies the intimacy of subjectivity.

KEYwORDS: Community, Bataille, sacrifice, meaning, sovereignty, subjectivity 


\section{FUNDAMENTOS DE LA COMUNIDAD EN GEORGES BATAILLE}

La obra de Bataille es sumamente compleja por la variedad de temas que abarca. Sus inquietudes filosóficas y su búsqueda personal lo llevaron a profundizar en áreas tan diversas como la antropología, la sociología, el arte, la literatura, la economía, el erotismo y el estudio de las religiones. A pesar de la heterogeneidad, parece haber constantes que le dan cierta forma y coherencia a su obra como una totalidad, la cual, sin embargo, no es susceptible de ser sistematizada. Una de esas constantes, a mi parecer, es la idea de que las comunidades humanas comparten cierto fundamento, cuya esencia escapa por completo a una conceptuación que permita establecer de manera clara y distinta los principios que rigen a las sociedades. Dicho fundamento, tiene consecuencias que se han manifestado a lo largo de la historia y que pueden ser estudiadas por medio de las diversas creaciones culturales, actividades o productos que desarrollan las sociedades. La concepción que Bataille tiene del funcionamiento y actividades comunales, por lo tanto, depende de cierta esencia indefinible mediante conceptos, pero identificable y expresable en términos que en este texto intentaré desarrollar.

Para Bataille, el sujeto y el mundo se levantan sobre un fondo indeterminado e incognoscible. Aunque las sociedades establecen un orden sistemático que organiza sus actividades a través de un uso del lenguaje que 
diferencia y clasifica los objetos asignándoles un nombre y una función, no poseen la capacidad de auto-fundamentarse. La causa radica en que el saber que determina las posibilidades humanas, con base en cálculos y especulaciones a futuro, no existe por sí mismo, sino sólo con el fin de cumplir cierta función en cierto contexto. En realidad "no existe nada que sea en última instancia; por encima del abismo, el mismo suelo es la ilusión de una seguridad". ${ }^{1}$ El lenguaje, pues, es incapaz de referir por medio de la ordenación positiva de los objetos y la postulación de principios, a los fundamentos del mundo, los individuos y las sociedades. Se puede decir, por tanto, que en la concepción de Bataille, la nada, la imposibilidad, el no-saber, es lo que está en la base de los sujetos y sus sociedades. Esta imposibilidad de definición fundamental nos lleva a una situación contradictoria: intentar hablar sobre la Nada mediante el lenguaje que permitió que el mundo fuera algo susceptible de ser utilizado planificadamente.

El hecho de que lo útil y lo posible hayan sido engendrados por el lenguaje, cuyo fundamento es la imposibilidad, nos pone ante la perspectiva de lo que podríamos llamar una doble faceta del lenguaje y de los

${ }^{1}$ Georges Bataille, "El planeta atestado", en La felicidad, el erotismo y la literatura. Ensayos 1944-1966, 2001, Buenos Aires, A. Hidalgo, p. 386. sujetos que constituye. El lenguaje puede ser utilizado para construir, como una herramienta al servicio del sistema y el futuro, o poéticamente, desarticulando el discurso de lo útil y lo posible, para manifestarnos a través de las fisuras, de los silencios, el verdadero fundamento de la subjetividad.

Toda la obra de Bataille parece estar determinada por esta dialéctica entre lo útil y lo poético, lo posible y lo imposible, cuya influencia teórica podemos encontrar en la filosofía de Hegel. En específico, la concepción hegeliana de la muerte y el sacrificio, gracias a la interpretación de Kojève, marca definitivamente todas las concepciones de Bataille sobre el tema que aquí nos interesa. Según esta interpretación, para la dialéctica hegeliana, el recorrido del espíritu hacia la conciencia de sí mismo comienza en la Nada misma: "Lo que existe es la noche, la interioridad o la intimidad de la Naturaleza: (el) Yo-personal puro". ${ }^{2}$ Esta nada fundamental se manifiesta como una acción negativa, libre y creadora, lo cual lleva a Bataille, siguiendo a Kojève, a calificar la filosofía hegeliana como una filosofía de muerte; no en el sentido de una fatalidad, sino de una muerte voluntaria que deriva de riesgos

${ }^{2}$ Georges Bataille, "Hegel, la muerte y el sacrificio", op. cit., p. 284. 
NOTAS

asumidos sin necesidad, lo cual vendría a ser la esencia humana.

La acción negativa es el movimiento del espíritu que, oponiéndose a la naturaleza, la niega "como una noche en la luz, como una intimidad en la exterioridad de esas cosas que son en si'. ${ }^{3}$ La intimidad, esa nada que constituye al sujeto, se manifiesta exteriormente oponiéndose a la naturaleza en una negatividad que la destruye y a la vez la transforma. La creación, acto característico de la humanidad, es, al mismo tiempo, destrucción y por ello transformación; es poesía, en tanto destrucción, y a la vez acción, en el sentido de trabajo y lucha en un contexto histórico. El mundo hegeliano, lo real concreto, es a la vez sujeto y objeto en constante transformación, pues su esencia recae sobre la nada que permite la acción negativa que es creadora.

La muerte y la creación permiten la historicidad, la individualidad y la libertad. Sólo porque el hombre crea y actúa en el horizonte de la muerte, porque pone en juego su mismo ser, se puede hablar de una dimensión temporal y de evolución de los individuos y las sociedades. La angustia ante la que el hombre se enfrenta en la inevitable lucha que debe llevar a cabo contra lo exterior, al ser conciente de su propia muerte, lo pone ante la alternativa de sucumbir al servilis-

${ }^{3} I b i d .$, p. 285. mo de la utilidad o de elegir la libertad del amo que arriesga completamente su vida. Claramente, estamos en una perspectiva en la que la voluntad y la decisión juegan un papel determinante. $Y$ es precisamente frente a la decisión de arriesgarse o de calcular las consecuencias, donde surge la posibilidad de la religión, la división de lo sagrado y lo profano, y la verdad misma del espíritu que sólo puede encontrarse a sí mismo "en el desgarramiento absoluto". ${ }^{4}$

La muerte, al igual que la destrucción, implica un alejamiento del mundo cotidiano y útil donde todo es medido con respecto a cierta duración. Esta separación determina a su vez los reinos de lo sagrado y lo profano. El acto en el que se consuma la ruptura, para Bataille, es el sacrificio. Existe sacrificio desde que el hombre, por medio de su acción negativa sobre la naturaleza, se separa del reino animal para establecer el reino de la utilidad; pero también existe cuando el hombre, que se encontraba sometido a una rutina especulativa, es capaz abrirse al despilfarro, el lujo, el gasto inútil y el placer voluptuoso. En y por el acto del sacrificio "la muerte vive una vida humana". ${ }^{5} \mathrm{El}$ sacrificio hace de la muerte un riesgo y una fuerza transformadora que determina el funcionamiento y desti-

${ }^{4}$ Ibid., p. 290.

${ }^{5}$ Ibid., p. 296. 
no de las sociedades. Las características de una sociedad dependen de aquello que sacrifican; de los riesgos que toman al decidir destruir recursos más allá del afán de conservar y acumular; de sus hábitos de consumo y gasto puros.

Ahora bien, ¿cómo puede el sacrificio manifestar la esencia interior del espíritu mediante de una acción exterior? Si la muerte y la nada son la esencia de la acción negativa del hombre, ¿cómo pueden los seres vivos pretender fundar en la muerte sus comunidades? La única manera posible de hacer de la muerte una institución social es la representación de un espectáculo, de una puesta en escena donde se viva el espectáculo "con la impresión de morir de verdad". ${ }^{6} \mathrm{El}$ sacrificio, en tanto representación, ejerce un efecto poético que nos vincula, más allá del discurso, con al ámbito de lo sagrado. A su vez, al formar parte de las prácticas que sustentan cierto orden, no es capaz de separarse del mundo profano.

El sacrificio, por convertirse en lenguaje mediante la representación, nos pone de nueva cuenta ante la oposición de dos contrarios fundamentales. Mientras que sirve para separar las dimensiones de lo sagrado y lo profano, a la vez las expresa en un solo acto. Quizás el sacrificio comparte las características de la experiencia

${ }^{6}$ Ibid., p. 298. interior. En palabras de Bataille, "la experiencia interior es un proyecto [...] Lo es, puesto que el hombre lo es por entero por el lenguaje [...] Pero el proyecto no es en este caso el de la salvación [...] sino el negativo de abolir el poder de las palabras y, por lo tanto, del proyecto". ${ }^{7}$ En este sentido, tal vez pueda suponerse que el sacrificio, a pesar de formar parte de algún proyecto social, pretende en última instancia abolir o al menos suspender, por un instante, el proyecto del cual forma parte. La pregunta que surge al respecto es: ¿por qué un proyecto ha de abolirse a sí mismo, como consecuencia de la interioridad sobre la que se funda? Para responder, tendríamos que imaginar una voluntad distinta a la voluntad de totalidad en la cual los individuos se unen para formar un sistema y vivir bajo las mismas normas. La voluntad que permite el sacrificio debería de ser aquella en la que:

La voluntad de transformase en todo fuese mirada como un obstáculo para la de perderse (la de escapar al aislamiento, al repliegue del individuo). ¡En la que transformarse en todo fuese tenido por el pecado no sólo del hombre, sino de todo lo posible e incluso de Dios mismo! ${ }^{8}$

${ }^{7}$ Georges Bataille, La experiencia interior, 1989, Madrid, Taurus, p. 33.

${ }^{8}$ Ibidem. 
NOTAS

Lo que llama la atención de la cita anterior es que la voluntad de totalidad no es el resultado de una especie de consenso entre individuos, sino por el contrario, un obstáculo para su aislamiento e inclusive su pecado. Lo que nos revela Bataille con estas palabras es la idea de lo que realmente nos une en comunidad. La voluntad de los hombres, desde esta perspectiva, no los lleva a unirse por un acto racional con el fin de asegurar la supervivencia. La comunicación que permite a los hombres unirse y escapar de su aislamiento "supone entre los que se comunican, no lazos formales, sino condiciones generales. Condiciones históricas, actuales, pero actuando en un cierto sentido". ${ }^{9}$ Dicho sentido es lo que parece ser decisivo para la constitución de la comunidad. Al no proceder de consideraciones formales, el sentido aquí mencionado parece no ser instituido en el discurso, sino, en todo caso, por la acción negativa que funda el discurso, es decir, en la experiencia misma. Por ejemplo, Bataille, al reflexionar sobre la vida, nos dice: "es de un sentimiento de comunidad que me une a Nietzsche de donde nace en mí el deseo de comunicación, no de una originalidad aislada". ${ }^{10}$ Lo que une aquí a Bataille con Nietzsche, haciendo de dicha unión una comunidad, es

${ }^{9}$ Ibid., p. 35.

${ }^{10}$ Ibid., p. 37. un sentimiento que constituye la experiencia misma y que no se puede diferenciar de ella. Se habla de una comunidad "sin otro objeto que la experiencia". " Al partir únicamente de ella, toda diferencia queda suprimida, ya que la experiencia en sí misma es anterior al acto de distinguir y poner límites. Implica, pues, la ausencia de distinciones. Por ello, al fundarse sobre ella la comunidad, se impide el aislamiento. La experiencia permite la comunicación porque ella misma es el punto extremo que nos identifica con el otro del cual nos hemos separado, al asignarle un nombre y una función: "No puedo cesar ni un instante de provocarme a mí mismo hacia el punto extremo y no puedo hacer diferencias entre mí mismo y los otros con los que deseo comunicarme". ${ }^{12}$ La comunidad no puede fundarse en el sistema, pues éste más bien significa su anulación. Lo que nos une, lo que nos vuelve un Todo, tiene que ver con aquellas experiencias que nos vinculan por medio de la esencia negativa que compartimos. El sacrificio que hemos mencionado podría propiciar dicho tipo de vivencia; de ahí el pecado que implica la totalidad. De igual forma, Bataille menciona otro tipo de situaciones análogas en el erotismo, la guerra, el despilfarro, etc. ¿Qué comparten todas estas formas de la

${ }^{11}$ Ibid., p. 38.

${ }^{12}$ Ibid., p. 51. 
experiencia que las vuelve necesarias en la constitución de la comunidad?

Como ya mencionamos, hay una tendencia a la unión, a la totalidad, que caracteriza a la experiencia interior. Sin embargo, al hablar de la influencia de Hegel sobre Bataille, mencionábamos también que la interioridad es al mismo tiempo la causa de la separación del hombre de la naturaleza y de otros hombres, colocándonos ante la disyuntiva de elegir entre el camino de la soberanía o de la servidumbre. Así pues, el sacrificio y otras experiencias análogas, ¿unen o separan? O, quizá deberíamos preguntarnos, ¿a qué nos unen y de qué nos separan?

La animalidad, para Bataille, equivale a la inmediatez o la inmanencia. El animal no tiene tiempo, historia o subjetividad; se encuentra más allá del discurso y por lo tanto es incognoscible. Puede ser expresado por la poesía, equivale a la intimidad y sólo es accesible gracias a la experiencia. Entre el mundo y el animal existe una continuidad constante; el animal no se ha separado de la naturaleza, tal como lo ha hecho el hombre, debido a que, para el animal, la muerte no significa nada; sólo significa para el hombre, porque la continuidad entre él y el mundo ya ha sido rota. Un asesinato tiene efecto en un hombre, por ejemplo, porque entre el asesino y la víctima hay una diferencia, una discontinuidad que el asesinato elimina, reestableciendo la continuidad. La muerte, pues, tiene el significado de reestablecer para el hombre la continuidad perdida. La discontinuidad, en cambio, surge con la conciencia que transforma al mundo, al elaborar útiles con vistas a cumplir un fin. Aquí, el instante pierde importancia, la cual es cedida al proyecto. Sin embargo, todos los fines que imponga el proyecto son relativos y nunca son verdaderos fines en sí mismos. El propio hombre, al entregarse a la utilidad, se convierte en una cosa, en una herramienta más. Regresar al mundo de la continuidad equivaldría a liberarse de las ataduras de todo proyecto, $\mathrm{y}$ al mismo tiempo, establecer la comunicación de la experiencia con los otros. Es lo que buscan el sacrificio, el erotismo, el despilfarro, la fiesta, entre otros.

Así, estas experiencias nos unen; vinculan lo previamente separado por la conciencia, sin que esto signifique que se regresa a la animalidad; la razón no cede su lugar a la violencia. Tenemos, pues, que existe una dualidad en el hombre. Por un lado, está la inmanencia de la experiencia y, por otro, la trascendencia de la razón sobre el mundo. El espíritu, por tanto, lleva a cabo dos tipos de movimiento: uno hacia la intimidad y otro hacia la discontinuidad. La primera 
NOTAS

separación del espíritu con respecto a la naturaleza, por su acción negativa, corresponde al movimiento de la trascendencia. La violencia, por la cual nos alejamos del mundo profano para experimentar la continuidad del orden sagrado, corresponde al movimiento hacia la intimidad.

Las sociedades permanecen en un movimiento constante que va del orden de la utilidad al de la soberanía y viceversa. Podemos presenciar dicha dinámica en sus estructuras sociales y sus jerarquías, pues a lo largo de la historia las sociedades han permitido que ciertas clases ejerzan la soberanía y que otras realicen las funciones de trabajo y transformación de la naturaleza, lo cual equivale a la dialéctica hegeliana del amo y el esclavo.

La obra de Bataille es rica en análisis y ejemplos de las diferentes configuraciones que, con el paso del tiempo, se han dado entre las clases soberanas y las serviles. Lo que en este punto podemos preguntarnos es: ¿qué significa la soberanía para Bataille y en qué se manifiesta? ¿Qué distingue a un soberano del resto de los humanos? ¿Qué hace posible que ambas clases convivan en sociedad?

Un soberano es, antes que cualquier otra cosa, un rebelde. Lo propio de la revuelta, por su parte, es no dejarse someter, ya sea por alguna autori- dad, ya por algún fin o función. Así, para que exista la soberanía, ésta debe estar precedida por una autoridad que sea capaz de sojuzgar al espíritu. Aquello que me someta con su autoridad, será soberano con respecto a mí. Dicha subordinación comienza con el establecimiento de un proyecto y de un mundo destinado a la utilidad. Los hombres que entregan su vida a realizar actividades útiles con miras a cumplir ciertos fines a futuro, han elegido la vida servil. Pero, al hacerlo, también engendraron una instancia soberana. Al arriesgarse a dedicar sus vidas a actividades fuera del terreno del cálculo racional, los hombres se rebelan a dicha instancia soberana y ellos mismos se convierten en soberanos. El soberano es quien está más allá del proyecto; quien, poniendo su vida en juego, deja de ser medio para un fin, haciendo de sí mismo el único fin.

Todos somos libres de elegir la muerte; sin embargo, mientras que el esclavo prefiere escoger el trabajo para evitar la muerte, el soberano elige la muerte como vida. El estado de soberanía es aquel que ya no tiene un más allá; aquel cuya riqueza se percibe en su propia destrucción y no en su conservación. Ahora bien, se puede decir, en general "que el soberano (o que la vida soberana) comienza cuando, asegurado lo necesario, la posibilidad de la vida se abre sin lími- 
te". ${ }^{13}$ La soberanía sólo es posible tras cierto grado de desarrollo, el cual no sólo permite sobrevivir, sino que también proporciona al soberano el goce de las posibilidades que la utilidad no justifica, el gasto que va más allá de la mera producción y que, sin embargo, no es razón de ser de esta última, aunque la necesite (los esclavos no justifican a los soberanos, pero unos no existen sin los otros). Conocer y trabajar, por tanto, no tienen nada que ver con el goce del soberano. Para éste, su objeto se resuelve en Nada; "se hace soberano dejando de ser". ${ }^{14}$

La rebelión por medio de la cual el soberano alcanza tal estado parte de la previa imposición de lo que se ha llamado interdicto. El interdicto es una prohibición de carácter moral, ligada al mundo profano de la utilidad y, por lo tanto, al mundo exterior, al de las cosas útiles. Su trasgresión está orientada más bien al interior. Lo que mueve a un hombre a violar la prohibición y a poner en riesgo su vida es la angustia que provoca la imposición de la norma; a su vez, la violación también es susceptible de provocar angustia. La vida siempre está en juego. Hay conflictos en el orden de la experiencia que no pueden objetivarse ni ser conocidos por la razón, pero que funcionan como causas

${ }^{13}$ Georges Bataille, Lo que entiendo por soberanía, 1996, Barcelona, Paidós I.C.E/ U.A.B, p. 64.

${ }^{14}$ Ibid., p. 71. reales de las acciones de los hombres. Como dice Bataille, refiriéndose al erotismo, que es una forma de soberanía: "la experiencia interior del erotismo requiere, en el que la vive, una sensibilidad no menos grande para la angustia, que funda el interdicto, que para el deseo que conduce a infringirlo". ${ }^{15}$

La interioridad, como fundamento negativo, siempre es la base de todo movimiento del espíritu, en tanto que vive y se angustia. El rumbo a elegir, ya sea el sometimiento a la norma o la trasgresión, determina la soberanía o el servilismo. Como sea, en ningún caso existen criterios morales, físicos o metafísicos para determinar qué rumbo ha de tomar la conciencia. Recordemos que, cuando hablamos de intimidad, siempre estamos, por esencia, ante la ausencia de cualquier tipo de saber. Se trata, en todo caso, de un movimiento violento "que siempre excede los límites y que jamás puede ser reducido parcialmente", ${ }^{16}$ donde el exceso se manifiesta como "la medida en que la violencia vence a la razón". ${ }^{17}$ Por violencia, podemos entender principalmente aquello que, si no es contenido, destruirá a los hombres o a la sociedad que asegura la conservación de los hombres. De ahí la razón del interdicto, el cual,

${ }^{15}$ Georges Bataille, El erotismo, 1992, Barcelona, Tusquets Editores, p. 56.

${ }^{16}$ Ibid., p. 58

${ }^{17}$ Ibid., p. 59. 
NOTAS

según Bataille, afecta primeramente a la muerte y a la función sexual (en tanto prohibiciones del asesinato y el incesto). Es muy importante destacar que, por el movimiento mismo del espíritu, la esencia misma del interdicto es la trasgresión y viceversa; son como dos caras de una misma moneda. Un interdicto prácticamente es postulado para ser transgredido, de la misma forma que su trasgresión sólo tiene sentido por la represión angustiosa que provoca la prohibición. ¿Hay, por tanto, razones para prohibir y transgredir? La razón misma es la que impone el interdicto, pero un fundamento más profundo, del orden de la experiencia, la cual es incognoscible en sí misma, es lo que nos mueve a transgredir. Así, no hay razón alguna para transgredir; ni siquiera se puede decir que la trasgresión en sí misma produzca placer. Simplemente, la vida mueve al hombre a ello de manera arbitraria; se trata de una cuestión de suerte. En todo caso, lo único que puede llevar a cabo la voluntad es acceder a dicho movimiento o reprimirse. Nada hay en la soberanía que nos lleve a pensar que hay una especie de recompensa por llegar a ella. "La moral es necesariamente el combate contra el erotismo y el erotismo, necesariamente, sólo tiene lugar en la inseguridad de un combate". ${ }^{18}$

${ }^{18}$ Georges Bataille, "El erotismo, sostén de la moral", en La felicidad, el erotismo y la literatura, op. cit., p. 382.
A pesar de que el estado de soberanía no ofrece ninguna garantía para la supervivencia, "vivir soberanamente es escapar, si no de la muerte, al menos de la angustia de la muerte", ${ }^{19}$ pues ésta es producto de la prohibición, que ha establecido un orden de las cosas en el que la subordinación a un plan a futuro es la norma. El soberano, entonces, no se toma en serio su propia muerte, aunque viva de ella. "Lo que el soberano se toma en serio no es la muerte del individuo, sino a los otros: prefiere, al hecho de sobrevivir personalmente, un prestigio que ya no le engrandecerá si muere, y que sólo contará en la medida que los otros cuenten". ${ }^{20}$ La soberanía exige la fuerza de violar las prohibiciones y la destrucción; sin embargo, en tanto que la propia vida del soberano pasa a segundo término para él, mientras que los otros (y el efecto que tenga sobre ellos), al primer plano, lo que le queda es el asesinato; el soberano es un asesino.

La conciencia de la propia muerte a manos del soberano provoca que los subordinados lo vean, en primera instancia, no como a un objeto más, no como a uno de ellos, sino como a la expresión misma de la subjetividad; se convierte a sus ojos en una manifestación de la experiencia interior

${ }^{19}$ Georges Bataille, Lo que entiendo por soberanía, op. cit., p. 83.

${ }^{20}$ Ibid., p. 84. 
profunda. Un ser como éste no puede dedicarse al trabajo, sino que, por el contrario, se ocupa de consumir -lo cual es una forma de destrucción-el trabajo de los otros. El soberano, pues, se convierte en el derrochador indiferente de la comunidad; se encarga de darle salida a todo el excedente acumulado por la producción.

Aunque la dinámica anterior resulta absurda a la luz de la razón, es importante destacar que lo que aquí se pone en juego son estados de ánimo; flujos energéticos que provocan afecciones comunicables: "la soberanía es una institución porque la masa no le es ajena, porque el estado de ánimo del soberano, del sujeto, subjetivamente se comunica a aquellos de los que es soberano [...] se comunica de sujeto a sujeto por un contacto sensible de la emoción". ${ }^{21}$ En esta dinámica, los objetos que en primera instancia eran útiles, cuya función era su fin, se vuelven simples intermediarios que son reducidos a la insignificancia, para ser destruidos en su consumo. Lo importante de este sacrificio es que la comunicación interior de la soberanía permite reconocer en el soberano a un hermano, en el reconocimiento del esclavo en sí mismo de aquello que es propio del soberano, lo cual eleva a los subordinados, de cosas dedicadas al trabajo, a la cate- goría de sujetos, en la que la figura del soberano ya no representa nada ajeno. De aquí el fin de la soberanía, de sus ritos sacrificiales y de su esplendor: "indica el carácter miserable del trabajo pero pretende, al mismo tiempo que lo indica, elevarse por encima de él". ${ }^{22}$ A los ojos de los esclavos, el amo se convierte en un semejante que ofrece una representación a sus deseos; una imagen de aquello hacia lo cual pueden llegar ellos mismos, si y sólo si se rebelan y transgreden las prohibiciones que impone el soberano, poniendo su propia vida en juego (recordar que el soberano es esencialmente un asesino).

Los ejemplos de soberanía que Bataille expone a lo largo de su obra resultan sumamente interesantes. Desde líderes militares y religiosos, reyes y emperadores, hasta miembros del hampa y personajes sadeanos, todos comparten las características previamente mencionadas. Todos han transgredido el orden del trabajo y ejercen una función en la que los esfuerzos y recursos de la sociedad son dirigidos hacia su figura, con el fin de que los gasten, sin mayor justificación que la que les da su autoridad, en tanto que se arriesgan a tomar las decisiones y a morir en todo momento, incluso a manos de quienes generan los productos para que ellos puedan mantener su estilo de vida. 
NOTAS

Lo anterior resulta inexplicable bajo el punto de vista de teorías que abordan las relaciones de producción con base, únicamente, en la superación de la escasez y en el mejoramiento del nivel de vida de la mayoría. Con el fin de fundamentar estos sucesos y hacerlos inteligibles, Bataille desarrolló toda una teoría económica basada en el gasto improductivo y el derroche de la energía excedente que las condiciones de producción en un momento determinado no son capaces de utilizar para aumentar su capacidad. Este enfoque impide distanciarse de los actores sociales, convirtiéndolos en objeto de estudio, pues éstos deben ser estudiados no como meros productores que cumplen funciones claras y distintas, sino como sujetos "en su punto de ebullición". ${ }^{23}$ Desde esta perspectiva, la necesidad no determina en absoluto las posibilidades de la comunidad; es el excedente y el lujo lo que plantea los problemas fundamentales de la economía general, lo cual, de nueva cuenta, nos obliga a que centremos nuestra atención en el consumo, la destrucción, la muerte y el erotismo, en tanto formas de reproducción voluptuosa.

La razón y los criterios formales tienen poco que hacer aquí. No hay principios que sean capaces de establecer cómo han de ser utilizados

${ }^{23}$ Georges Bataille, La parte maldita, 1987, Barcelona, Editorial Icaria, p. 48. los recursos. Se habla únicamente de cantidades de energía disponible; energía bruta, sin dirección, que no puede ser aprovechada debido a que las condiciones materiales existentes son insuficientes para su inversión productiva; energía que tan sólo ofrece la posibilidad de ser dilapidada. Se trata de una economía de la soberanía y no del trabajo, pues éste tan sólo puede explicar las operaciones más básicas, es decir, aquellas encaminadas a satisfacer las necesidades naturales.

Recordemos que lo propio del hombre es romper con su naturaleza y transgredir sus límites. La antropología filosófica de Bataille, a partir de la cual ha sido posible determinar la esencia humana, basándose en la dialéctica hegeliana, funciona como base teórica de una sociología y una economía que hacen inteligible el funcionamiento de las comunidades, el cual, paradójicamente, escapa a todo concepto y definición al fincarse en la imposibilidad de la vivencia de la muerte y el gasto destructivo que implica tender perpetuamente a ella.

Por los desarrollos realizados en este texto, podemos concluir lo que para Bataille son los fundamentos de las comunidades humanas. Partiendo de un punto de vista en el que se intenta llevar a cabo una reflexión que ofrezca inteligibilidad a los proble- 
mas fundamentales de los hombres por medio de la dilucidación, no de las condiciones objetivas que permiten el establecimiento de comunidades, sino de la subjetividad de los actores involucrados, el método que sigue Bataille tiene que involucrar, necesariamente, la propia experiencia del autor y hacer de su misma vivencia el objeto de reflexión privilegiado. No estudia, por tanto, los hechos de la humanidad como si fueran algo exterior a él, sino reconociendo en ellos los rasgos que en su propia subjetividad pueden ser considerados como fundamentales. Así pues, se puede asegurar que plantea la ausencia absoluta de principios o fundamentos externos sobre los cuáles los hombres levanten sus comunidades y den sentido a sus actividades como seres sociales.

Los fundamentos de la comunidad humana se encuentran, para Bataille, en la interioridad de los hombres, la cual, sin embargo, plantea la dificultad de no poder ser estudiada conceptualmente, de una manera clara y distinta como si fuera un objeto. Lo único que le queda a nuestro autor es intentar expresar de la manera más coherente y auténtica posible su propia experiencia interior y suponer que ello sucede de la misma forma en todos los demás sujetos, en tanto que compartimos cierta esencia, la cual, en opinión de Bataille, consiste en supe- rar constantemente los límites a los cuales el espíritu, que en un primer momento es definido como Nada, se ha de enfrentar.

La superación implica destrucción y muerte: de lo otro en primera instancia, y de uno mismo, en tanto que es nuestra propia vida la que se pone en riesgo en los constantes enfrentamientos con la exterioridad. La posibilidad de destrucción de lo otro nos coloca en situación de trascendencia con respecto a ello; nos vuelve sus soberanos y nos libera de las necesidades que nos impone, dotándonos de la capacidad de gastar inútilmente, independientemente de cualquier consideración futura, enfatizando la vivencia del instante presente.

La soberanía absoluta implicaría la muerte absoluta (de lo otro en la conciencia absoluta de sí mismo) y la satisfacción total, es decir, el fin de toda posibilidad de enfrentamiento, una vez que todo haya sido consumido. Esto nos recuerda el fin de la historia hegeliano, el cual no debe ser visto como una predicción, sino como un recurso literario que intenta expresar los límites posibles de la subjetividad y abrirnos, al mismo tiempo, al horizonte de la imposibilidad de la muerte que el silencio de la destrucción final pone ante nosotros. Así, ante la pregunta sobre qué le queda al soberano después de haber consumido todos los recursos posibles que 
la comunidad produjo para él, la filosofía como la que culmina en el respuesta no puede ser pronunciada, sistema hegeliano. Las posibilidades sino en todo caso, expresada indidel lenguaje nos permiten expresar y rectamente por medio de los silencomunicar cosas distintas a concepcios que la poesía engendra con sus palabras. tos y palabras que designan objetos identificables en un plano cartesiano.

La subjetividad y la comunidad se Bataille reconoce esto y lo explota, sostienen sobre la Nada; sin embargo, elaborando una obra que termina por para Bataille no significa el fin de la filosofía, sino el comienzo de un nuevo modo de filosofar. En todo caso, podría significar, tan sólo, el fin de una comunicarnos la intimidad de su subjetividad, la cual cada uno de sus lectores es capaz de reconocer mediante su propia experiencia, en sí mismo. 